\title{
Respon Komunitas Paradise Striver terhadap Dakwah Ustadz Abu Takeru
}

\author{
Neng Rita Trisna Wati ${ }^{1 *}$, Encep Taufik Rahman', \& Uwoh Saepuloh2 \\ ${ }^{1}$ Jurusan Komunikasi dan Penyiaran Islam, Fakultas Dakwah dan Komunikasi, \\ UIN Sunan Gunung Djati, Bandung \\ 2Jurusan Manajemen Dakwah, Fakultas Dakwah dan Komunikasi, \\ UIN Sunan Gunung Djati, Bandung \\ *Email: ritatrisna02@gmail.com
}

\begin{abstract}
This paper aims to determine the response of attention, understanding, and acceptance of the Paradise Striver Community towards the mission of Abu Takeru. In this research, the method used is descriptive method using quantitative approach. The study used questionnaire as the instrument filled out by respondents who are members of the community. Sampling of 50 respondents was taken by using the Taro Yamane formula. shows that the bypothesis Ha was accepted while $H o$ was rejected. The variable $x$ has a positive response to the variable $y$. The results of the calculation of Path Analysis (Coefficient of etermination) produces $R 2$ of 0.612 or $61.2 \%$. This shows a bigh significance level with the percentage of response contribution of variable $x$, and variable $y$ at $61.2 \%$ meanwhile, the remaining of $38.8 \%$ are in fluenced or explained by other variables that are not examined by the researchers.
\end{abstract}

Keywords: dakwah; response; community

\begin{abstract}
ABSTRAK
Tulisan ini bertujuan untuk mengetahui respon perhatian, pengertian, dan penerimaan Komunitas Paradise Striver terhadap dakwah Abu Takeru. Metode penelitian yang digunakan adalah metode deskriptif dengan pendekatan kuantitatif. Penelitian menggunakan kuesioner diisi oleh responden yang bertindak sebagai anggota Komunitas. Pengambilan sampel sebanyak 50 responden, diambil menggunakan rumus Taro Yamane. Hasil penelitian respon perhatian, pengertian, dan penerimaan Komunitas Paradise Striver terhadap Dakwah Abu Takeru, menghasilkan hipotesis Ha diterima dan Ho ditolak. Variabel x memiliki respon positif terhadap variabel y. Perhitungan Analisis Path (Koefisien Determinasi) menghasilkan R2 sebesar 0,612 atau sebesar 61,2\%. Hal ini menunjukan tingkat signifikansi yang kuat dengan persentase sumbangan respon variabel $\mathrm{x}$, dan variabel y sebesar $61,2 \%$. Sedangkan sisanya 38,8\% dipengaruhi atau dijelaskan oleh variabel lain yang tidak diteliti oleh peneliti.
\end{abstract}

Kata Kunci : dakwah; respon; komunitas 


\section{PENDAHULUAN}

Dakwah merupakan serangkaian bahasa yang memiliki makna besar, untuk dipertanggung jawabkan di kemudian hari. Dalam menjalankan dakwah, mad'u membutuhkan rangkulan yang dapat dipercaya, sebagai sandaran keimanan dalam mengarungi perjalanan hidup. Dijalankan oleh da’i dalam kemurnian Al-Qur'an, sebagai pedoman hakiki umat secara universal (rahmatan lil alamiin). Sehingga hari esok adalah masa depan da'i yang menjadi harapan akan keberhasilan dakwah, dengan kesabaran yang menyelimuti raga, tutur kata, dan langkahnya.

Karena cinta melahirkan tanggung jawab, maka terlalu haram bagi penista, dan penganiyaya untuk menghirup ketentraman. Ketika kita mempercayai AlQur'an merupakan Kalamullab secara hakiki, keyakinan seluruhnya hanya akan digerakan oleh Sang Pencipta. Dengan ilmu dan kecintaan yang teramat dalam, seorang da'i memiliki tanggung jawab untuk membimbing dan mengarahkan yang menjadi tanggung jawabnya. Firman Allah SWT:

"Serulah (manusia) pada jalan Tubanmu dengan bikmah dan pengajaran yang baik,

dan berdebatlah dengan mereka dengan cara yang baik. Sesunggubnya Tuhanmu

Dialah yang lebih mengetabui siapa yang sesat dari jalan-Nya dan Dialah yang lebih

mengetabui siapa yang mendapat petunjuk”. (Depag RI, 2004:281)

Dengan kemampuan penalaran, manusia menjadikan ia mampu untuk menjelajah pengetahuan yang merupakan salah-satu jembatan menuju kekuasaan. Lewat sebuah penalaran, manusia mengenal nilai yang mana di dalamnya terkandung perbedaan baik, buruk, benar, dan salah. Sehingga secara terus menerus manusia dituntut untuk memilih hal serupa. Dengan begitu ia akan menegok pada pengetahuan lain sebagai pilihannya. (Ika, 2009:127)

Dalam membumikan dakwah, ajaran Islam perlu diketahui oleh umat manusia secara universal, dipahami, dihayati, dan dilaksanakan. Tentulah juru dakwah yang berkualitas sejatinya orang-orang yang mengerti hakikat Islam, paham penomena yang sedang berkembang di masyarakat. Suksesnya dakwah ditentukan oleh bebet dan bobotnya seorang da'i. Dengan kualitas, Islam akan mendapatkan kreadibilitas serta citra da'i yang positif di mata mad'u, individu maupun masyarakat. (Enjang, 2009:120)

Di zaman yang modern relativasi moral menjadi tujuan utama, untuk mengangkat derajat kemanusiaan. Manusia sibuk berhamburan di muka bumi, demi mengejar setitik cahaya tanpa melihat adanya sumber cahaya yang jauh lebih besar, padahal keduanya ada dihadapan mereka. Sehingga seorang da'i harus jauh lebih paham mengenai keinginan dan harapan mad'unya. Cara tersebut, bisa memudahkan penyampaian pesan Islam pada mad'u. Perlu diketahui, dalam agama Islam, manusia tidak perlu bersusah payah mencari keadilan nilai moral, maka kata adil merupakan jaminan yang ditawarkan, tentulah nilai-nilai moral akan menjulang dengan sendirinya. Jika hal itu belum didapatkan, tampaknya nilai Islam belum digali, sehingga sulit untuk merasakan apa yang sesungguhnya ada dalam Islam. 
Oleh karena itu, seorang mad'u berhak tahu tentang kebenaran al-quran dan as-sunnah yang sampai kepadanya lewat seorang da'i. Selain itu, harus ada ikatan kuat baik kedekatan maupun kepercayaan antara da'i dan mad'u. Karena cerminan da'i sangat berpengaruh pada mad'u. Da'i yang berkualitas akan melahirkan mad'u yang berkualitas pula, begitupun sebaliknya.

Fakta yang sesuai dari kesaksian sejarah, bahwa bukti-bukti Al-Qur'an dan berbagai petunjuk nakli dan aqli yang berderet bersumberkan sejarah Islam, maka dapat dikatakan bahwa pikiran Rasulullah saw, sama sekali tidak tersentuh oleh ajaran manusia walaupun hanya dasarnya. Beliau langsung diajar oleh Ruh Illabi dan pengetahuan diperoleh dari wujud Dia sendiri. Nabi Muhammad saw merupakan bunga yang mekar dan sumerbak wangi hasil dipupuk oleh pemilik kebun pra keabadian didirikan (Muthahhari, 1997:67).

Dakwah merupakan serangkaian bahasa yang memiliki makna besar, untuk dipertanggung jawabkan di kemudian hari. Dalam menjalankan dakwah, mad'u membutuhkan rangkulan yang dapat dipercaya, sebagai sandaran keimanan dalam mengarungi perjalanan hidup. Dijalankan oleh da'i dalam kemurnian Al-Qur'an, sebagai pedoman hakiki umat secara universal (rabmatan lil alamiin). Sehingga hari esok adalah masa depan da'i yang menjadi harapan akan keberhasilan dakwah, dengan kesabaran yang menyelimuti raga, tutur kata, dan langkahnya.

Karena cinta melahirkan tanggung jawab, maka terlalu haram bagi penista, dan penganiyaya untuk menghirup ketentraman. Ketika kita mempercayai AlQur'an merupakan Kalamullah secara hakiki, keyakinan seluruhnya hanya akan digerakan oleh Sang Pencipta. Dengan ilmu dan kecintaan yang teramat dalam, seorang da'i memiliki tanggung jawab untuk membimbing dan mengarahkan yang menjadi tanggung jawabnya. Firman Allah SWT:

"Serulah (manusia) pada jalan Tuhanmu dengan hikmah dan pengajaran yang baik, dan berdebatlah dengan mereka dengan cara yang baik. Sesunggubnya Tubanmu Dialah yang lebih mengetahui siapa yang sesat dari jalan-Nya dan Dialah yang lebih mengetahui siapa yang mendapat petunjuk”. (Depag RI, 2004:281)

Dengan kemampuan penalaran, manusia menjadikan ia mampu untuk menjelajah pengetahuan yang merupakan salah-satu jembatan menuju kekuasaan. Lewat sebuah penalaran, manusia mengenal nilai yang mana di dalamnya terkandung perbedaan baik, buruk, benar, dan salah. Sehingga secara terus menerus manusia dituntut untuk memilih hal serupa. Dengan begitu ia akan menegok pada pengetahuan lain sebagai pilihannya (Ika, 2009:127).

Dalam membumikan dakwah, ajaran Islam perlu diketahui oleh umat manusia secara universal, dipahami, dihayati, dan dilaksanakan. Tentulah juru dakwah yang berkualitas sejatinya orang-orang yang mengerti hakikat Islam, paham penomena yang sedang berkembang di masyarakat. Suksesnya dakwah ditentukan oleh bebet dan bobotnya seorang da’i. Dengan kualitas, Islam akan mendapatkan kreadibilitas serta citra da'i yang positif di mata mad'u, individu maupun masyarakat (Enjang, 2009:120).

Di zaman yang modern relativasi moral menjadi tujuan utama, untuk 
mengangkat derajat kemanusiaan. Manusia sibuk berhamburan di muka bumi, demi mengejar setitik cahaya tanpa melihat adanya sumber cahaya yang jauh lebih besar, padahal keduanya ada dihadapan mereka. Sehingga seorang da'i harus jauh lebih paham mengenai keinginan dan harapan mad'unya. Cara tersebut, bisa memudahkan penyampaian pesan Islam pada mad'u. Perlu diketahui, dalam agama Islam, manusia tidak perlu bersusah payah mencari keadilan nilai moral, maka kata adil merupakan jaminan yang ditawarkan, tentulah nilai-nilai moral akan menjulang dengan sendirinya. Jika hal itu belum didapatkan, tampaknya nilai Islam belum digali, sehingga sulit untuk merasakan apa yang sesungguhnya ada dalam Islam.

Oleh karena itu, seorang mad'u berhak tahu tentang kebenaran al-quran dan as-sunnah yang sampai kepadanya lewat seorang da'i. Selain itu, harus ada ikatan kuat baik kedekatan maupun kepercayaan antara da'i dan mad'u. Karena cerminan da'i sangat berpengaruh pada mad'u. Da'i yang berkualitas akan melahirkan mad'u yang berkualitas pula, begitupun sebaliknya.

Fakta yang sesuai dari kesaksian sejarah, bahwa bukti-bukti Al-Qur'an dan berbagai petunjuk nakli dan aqli yang berderet bersumberkan sejarah Islam, maka dapat dikatakan bahwa pikiran Rasulullah saw, sama sekali tidak tersentuh oleh ajaran manusia walaupun hanya dasarnya. Beliau langsung diajar oleh Ruh Illabi dan pengetahuan diperoleh dari wujud Dia sendiri. Nabi Muhammad saw merupakan bunga yang mekar dan sumerbak wangi hasil dipupuk oleh pemilik kebun pra keabadian didirikan. (Muthahhari, 1997:67)

Seorang da'i harus memiliki strategi yang dapat mengimbangi penyusutan gaya hidup (life style) yang beredar dilingkungan masyarakat. Agar dakwah tetap terlihat indah dalam kemasannya, tanpa menghilangkan kemurniannya. Salah satu strategi yang digunakan Abu Takeru yaitu membuat suatu halakoh (perkumpulan) dengan sebutaN Komunitas Paradise Striver (Pejuang Surga), yang dulunya kelompok ini di persatukan karena memiliki kesamaan, yakni sama-sama menyukai anime. Salah satu keberhasilan Abu takeru adalah berhasil mengubah sekelompok pecinta anime menjadi komunitas paradise striver (pejuang surga).

Berdasarkan data yang diproleh dari Abu Takeru selaku pendiri sekaligus pembina komunitas Paradise Striver di Masjid Al-Asy’ari. Bahwa Komunitas Paradise Striver mengalami perjalanan yang cukup panjang, dari tahun ke tahun yang bermula pada tahun 2010. Pada awalnya sebatas perkumpulan segelintir orang, yang menyukai anime kemudian komunitas tersebut mengubah citra anime menjadi lebih positif. Perjuangan dan kegigihan Abu Takeru dalam mengemban dakwah sangat kuat, beliau tidak menghiraukan perkataan orang dengan sebutan (labeling) ekstrim yang pernah menghampirinya. Justru dengan labeling ekstrim, beliau terus membuktikan bahwa dakwah yang disampaikan benar adanya sesuai dengan Al-Qur'an dan As-Sunnah.

Data yang lain menyebutkan bahwa kehadiran ikhwan mapun akhwat dalam mengikuti kajian dakwah Abu Takeru cenderung bertambah, bahkan setiap harinya selalu dihadiri jama'ah baru. Hal ini menjadikan Komunitas Paradise Striver 
meningkat, bukan hanya remaja melainkan orang tuapun mulai tertarik untuk mengikuti kajian, meskipun kajian ditunjukkan lebih kepada generasi muda. Mengupas penjelasan di atas, terlihat jelas keseriusan para ikhwan maupun akhwat untuk berjuang mendapatkan Ridha Allah SW'T melalui dakwah Abu Takeru.

Harapan untuk komunitas, "sebenarnya bukan keinginan komunitas agar memiliki banyak anggota. Di lubuk hati yang terdalam, tentu ada keinginan agar hidayah Allah SWT tersebar. Orang mau ikut Komunitas Paradise Striver atau komunitas manapun, yang penting ajaran Al-Qur'an dan As-Sunnah sampai. Karena tujuan Komunitas Paradise Striver adalah memperkuat ikatan Agama Islam, tentu komunitas ini harus berbaur dengan komunitas lain selama sama-sama mengajak kebaikan." (Ungkap Abu Takeru ketika diwawancara pada tanggal 13 Mei 2018)

Dari latar belakang di atas, ditemukan beberapa masalah yang cukup menarik untuk ditelusuri: Bagaimana perhatian Komunitas Paradise Striver terhadap Abu Takeru?, Bagaimana pengertian Komunitas Paradise Striver terhadap dakwah Abu Takeru? Dan, Bagaimana penerimaan Komunitas Paradise Striver terhadap pesan dakwah Abu Takeru?.

Metode yang digunakan dalam penelitian ini adalah metode deskriptif (descriptive research) dengan pendekatan kuantitatif. Metode deskriftif yaitu suatu metode yang menjelaskan secara sistematis, faktual, dan akurat tentang fakta, mengenai sifat populasi di daerah tertentu. (Sumadi, 1998:18)

Alasan penggunaan metode ini, adalah untuk menyesuaikan dengan tujuan penelitian yang hendak dicapai. Adapun tujuannya yaitu mengungkapkan dan menggambarkan penelitian melalui hasil perhitungan respon perhatian, pengertian, dan penerimaan Komunitas Paradise Striver terhadap dakwah Abu Takeru di Masjid Al-Asy'ari.

Seorang da'i harus memiliki strategi yang dapat mengimbangi penyusutan gaya hidup (life style) yang beredar dilingkungan masyarakat. Agar dakwah tetap terlihat indah dalam kemasannya, tanpa menghilangkan kemurniannya. Salah satu strategi yang digunakan Abu Takeru yaitu membuat suatu halakoh (perkumpulan) dengan sebutaN Komunitas Paradise Striver (Pejuang Surga), yang dulunya kelompok ini di persatukan karena memiliki kesamaan, yakni sama-sama menyukai anime. Salah satu keberhasilan Abu takeru adalah berhasil mengubah sekelompok pecinta anime menjadi komunitas paradise striver (pejuang surga).

Berdasarkan data yang diproleh dari Abu Takeru selaku pendiri sekaligus pembina komunitas Paradise Striver di Masjid Al-Asy'ari. Bahwa Komunitas Paradise Striver mengalami perjalanan yang cukup panjang, dari tahun ke tahun yang bermula pada tahun 2010. Pada awalnya sebatas perkumpulan segelintir orang, yang menyukai anime kemudian komunitas tersebut mengubah citra anime menjadi lebih positif. Perjuangan dan kegigihan Abu Takeru dalam mengemban dakwah sangat kuat, beliau tidak menghiraukan perkataan orang dengan sebutan (labeling) ekstrim yang pernah menghampirinya. Justru dengan labeling ekstrim, beliau terus membuktikan bahwa dakwah yang disampaikan benar adanya sesuai 
dengan Al-Qur'an dan As-Sunnah.

Data yang lain menyebutkan bahwa kehadiran ikhwan mapun akhwat dalam mengikuti kajian dakwah Abu Takeru cenderung bertambah, bahkan setiap harinya selalu dihadiri jama'ah baru. Hal ini menjadikan Komunitas Paradise Striver meningkat, bukan hanya remaja melainkan orang tuapun mulai tertarik untuk mengikuti kajian, meskipun kajian ditunjukkan lebih kepada generasi muda. Mengupas penjelasan di atas, terlihat jelas keseriusan para ikhwan maupun akhwat untuk berjuang mendapatkan Ridha Allah SW'T melalui dakwah Abu Takeru.

Harapan untuk komunitas, "sebenarnya bukan keinginan komunitas agar memiliki banyak anggota. Di lubuk hati yang terdalam, tentu ada keinginan agar hidayah Allah SWT tersebar. Orang mau ikut Komunitas Paradise Striver atau komunitas manapun, yang penting ajaran Al-Qur'an dan As-Sunnah sampai. Karena tujuan Komunitas Paradise Striver adalah memperkuat ikatan Agama Islam, tentu komunitas ini harus berbaur dengan komunitas lain selama sama-sama mengajak kebaikan.” (Ungkap Abu Takeru ketika diwawancara pada tanggal 13 Mei 2018)

Dari latar belakang di atas, ditemukan beberapa masalah yang cukup menarik untuk ditelusuri: Bagaimana perhatian Komunitas Paradise Striver terhadap Abu Takeru?, Bagaimana pengertian Komunitas Paradise Striver terhadap dakwah Abu Takeru? Dan, Bagaimana penerimaan Komunitas Paradise Striver terhadap pesan dakwah Abu Takeru?.

Metode yang digunakan dalam penelitian ini adalah metode deskriptif (descriptive research) dengan pendekatan kuantitatif. Metode deskriftif yaitu suatu metode yang menjelaskan secara sistematis, faktual, dan akurat tentang fakta, mengenai sifat populasi di daerah tertentu. (Sumadi, 1998:18)

Alasan penggunaan metode ini, adalah untuk menyesuaikan dengan tujuan penelitian yang hendak dicapai. Adapun tujuannya yaitu mengungkapkan dan menggambarkan penelitian melalui hasil perhitungan respon perhatian, pengertian, dan penerimaan Komunitas Paradise Striver terhadap dakwah Abu Takeru di Masjid Al-Asy'ari.

\section{HASIL DAN PEMBAHASAN}

Penelitian ini dilakukan di Masjid Al-Asy'ari, Jl. Tamansari No. 1, Bandung Wetan, Kota Bandung, Jawa Barat 40116. Masjid Al-Asy'ari dibangun pada tahun 1977, seluas $\pm 300 \mathrm{M}^{2}$. Tanah pembangunan masjid merupakan pemberian dari Bapak. H. Asy'ari, sebagai bentuk penghargaan atas jasanya, para pendiri masjid mengabadikan namanya menjadi nama masjid, sehingga masjid tersebut bernama Masjid Al-Asy'ari. masjid terlihat megah menempati lantai dua, yang mampu menampung jamaah sebanyak \pm 1500 jama'ah.

Setelah pemugaran dilakukan, masjid Al-Asy'ari mulai terkenal keluar daerah dan makmur oleh jama'ah. Kemudian aktivitas kerohanian di masjid tersebut mengalami peningkatan. Selain itu, jadwal kajianpun tertata rapih setiap 
harinya oleh para Takmir masjid.

Seiring dengan perkembangan zaman, lahirlah kebijakan baru, tentang peleburan dua lembaga struktural yakni Lembaga Dakwah dan Koordinatorat Mata Kuliah Dasar Umum (MKDU) pada tahun 1988/1989, menjadi satu lembaga yaitu Lembaga Pembinaan Pendidikan Keagamaan dan Ilmu-Ilmu Dasar (LPPKID). Kemudian lembaga LPPKID ini membawahi tiga pusat, yaitu Pusat Pendidikan Agama Islam (PPAI), Pusat Pendidikan Ilmu-Ilmu Dasar (PPID), dan Pusat Pembinaan Kegiatan Masjid (PPKM). Semenjak itu Masjid Al-Asy'ari berada di bawah koordinasi PPKM, dan secara oprasional seluruh kegiatan yang ada di Masjid Al-Asy'ari dikelola oleh Pelaksana Harian Pusat Pembinaan Kegiatan Masjid (PH PPKM).

Sejak tahun 2008, pengurus masjid berada di bawah tanggung jawab pengelola harian Masjid Al-Asy'ari Universitas Islam Bandung (Unisba), yang didalamnya melibatkan unsur masyarakat dan seluruh orientasi kegiatan besar masjid-masjid di Tamansari berpusat pada Masjid Al-Asy'ari, terutama dalam kegiatan solat Idul Fitri dan Idul Adha. Hingga saat ini seluruh kegiatan Masjid Al-Asy'ari, secara oprasional dilaksanakan oleh Takmir masjid.

Pada awalnya Abu Takeru mengajikan surat izin untuk mengadakan kajian rutin setiap minggunya, kemudian pihak Takmir Masjid mengizinkan. Karena dilihat dari sisi strategis Maasjid AL-Asy'ari baik dari banyaknya mad'u maupun akses oprasional. Selain itu, santapan dakwah di Masjid AL-Asy'ari sangat dibutuhkan untuk mengimbangi pergaulan remaja di zaman sekarang.

Ustadz Rizal Fadli Nurhadi yang terkenal dengan sebutan Abu Takeru, lahir di Bandung, 1 September 1992. Pada tahun 2004 beliau harus ikut kepada sang ayah untuk melanjutkan kuliahnya di Australia. Pendidikan formal yang pernah ditempuhnya yaitu SDN Fans Setiabudi sekarang Labschool, kemudia sempat sekolah di SMP 12 Bandung selama satu bulan. Kemudian beliau melanjutkan pendidikannya di East Preston Islamic Collage pada tahun 2004-2007. East Preston Islamic Collage merupakan sekolah persamaan kesetaraan SD, SMP, dan SMA.

Selama di East Preston Islamic Collage, beliau mendapatkan hidayah dan manisnya Iman. Lewat para ulama beliau belajar hingga sekarang beliau terkenal. Tujuan beliau hanya satu yakni menyebarkan agama Allah SWT, agar semua orang tahu dan mempelajarinya. Itulah salah satu alasan beliau belajar secara itensif di Australia. Selama di sana beliau sempat belajar Agama Islam dengan teman-teman DR. Zakir Naik yang sedang melakukan Dauroh ke Melbourne University.

Pada tahun 2007 beliau pulang ke Indonesia, kemudian mutasi ke SMA Negeri 2 Bandung. Selama di SMA Negeri 2 Bandung, beliau menjadi ketua Lembaga Dakwah tahun 2008-2007. Beliau mulai berdakwah pada teman-teman di sekolah SMA Negeri 2 Bandung. Sayangnya setelah beliau lulus dari SMA Negeri 2 Bandung ada larangan, bahwa alumni dilarang mengisi kajian karena suatu hal, sehingga semua eskul dilarang mengisi. Semenjak adanya larangan tersebut, beliau bergabung ke ACC Alam Sugem Sugema bersama Yusuf Ibrahim. Kemudian membuat anggota halakoh di Masjid Pusdai, stelah halakoh tersebut banyak dikenal orang luar, lalu beliau mengikuti kajian mentoring gabungan di 
SMA 5 Bandung. Diluar dugaan, panitia menargetkan yang datang dalam mentoring tersebut sekitar 100 orang, namun yang datang lebih dari 500 orang. Setelah mentoring tersebut selesai, beliau diminta oleh pihak ITB untuk mengisi kajian di kharisma ITB yang bekerjasama dengan F'TI. Target jama'ah pada saat itu 100 orang, ternyata yang datang diluar dugaan juga yakni lebih dari 500 orang.

Awal mula Komunitas Paradise Striver didirikan, sekitar tahun 2010 lewat kajian yang awalnya sekitar 6 orang kemudian sampai 40 orang hingga ratusan orang, yang bernama Paradise Youth (Pemuda Surga), merupakan perkumpulan remaja yang menyukai anime, dan komunitas ini lebih aktif di dunia maya, karena kesibukan masing-masing anggota. Karena anggota Komunitas Paradise Youth (Pemuda Surga) menyukai anime, maka wajar jika salah satu agenda rutinnya memanfaatkan cuplikan film anime sebagai media dakwah. Seiring berjalannya waktu, setelah dimusyawarahkan kata Paradise Youth dianggap terlalu percaya diri (GR). Kemudian mendapatkan masukan juga dari salah satu guru Abu Takeru, sehingga komunitas ini berganti nama menjadi Komunitas Paradise Striver (Pejuang Surga). Setiap kegiatan Komunitas Paradise Striver hingga sekarang, didukung oleh CV. Miracle Glutaskin perusahaan milik Pak Ikhsan Yusuf.

Sasaran dakwah Komunitas Paradise Striver lebih ke anak-anak, dan remaja. Karena dilihat dari pengamatan saat ini, hampir seluruh pengajian yang ada di bandung mengarah atau fokus pada orang-orang dewasa, sehingga ada kekhawatiran anak-anak dan remajanya kurang mendapatkan perhatian. Sedangkan untuk mendapatkan kwalitas yang baik (pemuda-pemudi shaleh shalehah), seorang da'i harus memupuk ilmu sejak dini. Oleh karena itu, kebanyakan dari follower Komunitas Paradise Striver berasal dari kalangan anak SD, SMP, SMA, dan mahasiswa.

Dari penelitian ini ditemukan respon perhatian, pengertian, dan penerimaan Komunitas Paradise Striver terhadap Dakwah Abu Takeru sebagai berikut:

\section{Perhatian Komunitas Paradise Striver terhadap Abu Takeru}

Respon perhatian Komunitas Paradise Striver terhadap Abu Takeru dilihat dari ketaatan seluruh anggota Komunitas Paradise Striver (jamaah) terhadap perintah Abu Takeru baik anjuran maupun larangan, baik yang lebih tua dari Abu Takeru maupun yang lebih tua. Kemudian anggota Komunitas Paradise Striver selalu menghadiri kajian Abu Takeru. Selain itu, disetiap kota selalu ada anggota Komunitas Paradise Striver yang selalu setia mengikuti kajian Abu Takeru. Padahal dari 100\% yang menghadiri kajian, 95\% adalah seorang pelajar dan mahasiswa.

Respon erat kaitannya dengan proses kegiatan dakwah, baik yang sifat feedbacknya langsung maupun tidak langsung. Maka teori S-O-R yang digunakan dalam penelitian ini, dengan tiga aspek yaitu perhatian, pengertian, dan penerimaan. Agar dari kegiatan dakwah yang diteliti dapat dengan mudah mengetahui respon positif maupun negatif. (Tarwiyah, 2016:94)

Adapun kegiatan rutin Komunitas Paradise Striver yaitu kajian setiap hari 
Jum'at di Masjid Al-Asy'ari pukul 16:00-18:00 WIB, membahas Bab Taubid. Kemudian agenda rutin setiap hari Sabtu sampai Minggu pagi yaitu Tadzabur Alam, jalan-jalan ke suatu tempat yang di sana Komunitas Paradise Striver bisa main bersama, dakwah bersama, dan mensyukuri atas keindahan alam yang Allah SWT ciptakan. Biasanya setelah melaksanakan agenda Tadzabur alam, Komunitas Paradise Striver selalu membuat video pendek yang berisi nilai dakwah untuk di share, karena kegiatan demikian masuk kedalam salah-satu agenda Komunitas Paradise Striver. Kemudian agenda Minggu sorenya ada kajian lagi di Masjid STPBNHI, membahas Bab Fikih setiap pukul 16:00-18:00 WIB. Selain itu, Komunitas Paradise Striver juga memiliki agenda kunjungan ke setiap sekolahsekolah dengan cara mengajukan kerja sama dengan sekolah bersangkutan. Kebanyakan agenda kunjungan ini dimuat dalam bentuk tabligh akbar, tetapi kadang dimuat seperti kajian biasa. Adapun jadwal untuk kunjungan ke sekolahsekolah tidak menentu. Sudah puluhan sekolah baik SMP maupun SMA yang telah dihadiri Abu Takeru dan Komunitas Paradise Striver. Namun, apabila dibandingkan dengan Jakarta, jumlah sekolah yang dihadiri lebih banyak dari jumlah sekolah yang di Bandung. Karena di Jakarta Komunitas Paradise Striver lebih dikenal, terutama Jakarta Timur dan Jakarta Selatan. Jumlah sekolah yang pernah dihadiri di Jakarta lebih dari 100 sekolah, sehingga tidak bisa dihitung satu per satu.

\section{Pengertian Komunitas Paradise Striver terhadap Dakwah Abu Takeru}

Respon pengertian Komunitas Paradise Striver terhadap dakwah Abu Takeru, dapat diketahui dari hasil angket variabel x yang telah dianalisis. Angket yang digunakan dalam penelitian ini merupakan angket tertutup, dalam artian responden tinggal memilih pernyataan yang telah tersedia tanpa ada desakan. Dalam bentuknya digunakan angket skala linkert dengan alternatif responden memilih jawaban yang telah ditentukan dalam bobot nilai 1-5 yang telah disediakan dengan sekala linkert sesuai dengan pernyataan yang diajukan pada responden.

Tabel 1. Respon Komunitas Paradise Striver terhadap Dakwah Abu Takeru

\begin{tabular}{|c|c|c|c|c|c|}
\hline Pertanyaan & STS & TS & TP & S & SS \\
\hline $\begin{array}{l}\text { Komunitas Paradise Striver adalah } \\
\text { sekelompok orang yang mengejar surga. }\end{array}$ & 2 & - & 4 & 10 & 34 \\
\hline $\begin{array}{l}\text { Komunitas Paradise Striver } \\
\text { membuka wawasan saya bahwa berdakwah } \\
\text { tidak hanya dilakukan di atas mimbar saja, } \\
\text { melainkan dapat dilakukan dengan } \\
\text { berbagai macam cara. }\end{array}$ & - & - & 1 & 21 & 28 \\
\hline $\begin{array}{l}\text { Komunitas Paradise Striver } \\
\text { mengajarkan bahwa berdakwah itu asyik } \\
\text { dan menyenangkan. }\end{array}$ & - & - & 3 & 26 & 21 \\
\hline $\begin{array}{l}\text { Setelah bergabung dengan } \\
\text { Komunitas Paradise Striver, saya jadi } \\
\text { berhati-hati dalam bergaul dengan lawan } \\
\text { jenis. }\end{array}$ & - & - & 7 & 18 & 25 \\
\hline
\end{tabular}


N. R. T. Wati, R. T. Rahman, \& U. Saepuloh

\begin{tabular}{|c|c|c|c|c|c|}
\hline $\begin{array}{l}\text { Setelah bergabung dengan } \\
\text { Komunitas Paradise Striver, saya merasa } \\
\text { fakir ilmu dan ingin selalu mengkaji ilmu } \\
\text { baru. }\end{array}$ & 1 & 3 & 4 & 12 & 30 \\
\hline $\begin{array}{l}\text { Sebagai Komunitas Paradise Striver, } \\
\text { rasa ingin tahu saya terhadap ke-Esaan } \\
\text { Tuhan sangat tinggi. }\end{array}$ & - & - & 4 & 16 & 30 \\
\hline $\begin{array}{l}\text { Sebagai Komunitas Paradise Striver, } \\
\text { saya sangat antusias mengikuti kajian } \\
\text { Ustadz Abu Takeru. }\end{array}$ & - & - & 9 & 22 & 19 \\
\hline $\begin{array}{l}\text { Salah-satu kegiatan } \\
\text { Komunitas Paradise Striver yaitu } \\
\text { mengingating } \\
\text { san dalam kebaikan. }\end{array}$ & 1 & 1 & 2 & 20 & 26 \\
\hline $\begin{array}{l}\text { Setelah bergabung dengan } \\
\text { Komunitas Paradise Striver, saya menjadi } \\
\text { termotivasi untuk menyampaikan ilmu } \\
\text { yang saya dapatkan kepada orang lain. }\end{array}$ & - & 1 & 9 & 20 & 20 \\
\hline $\begin{array}{l}\text { Bergabung dengan Komunitas } \\
\text { Paradise Striver menjadi solusi alternatif } \\
\text { untuk belajar memahami dan mengkaji Al- } \\
\text { Qur'an serta As-Sunnah. }\end{array}$ & - & - & 5 & 24 & 21 \\
\hline
\end{tabular}

\section{Sumber: Instrumen Penelitian}

Hasil angket dari tabel 1 di atas, variabel x didukung oleh teori interaksi simbolik yang menjelaskan bahwa teori ini merupakan kerangka referensi yang menganalisis bagaimana manusia bersama dengan manusia lainnya, membangun karakter simbolik sehingga ada keterikatan. (Ricardh dan Lynn, 2012:125)

Teori interaksi simbolik menjelaskan bagaimana manusia yang satu dengan manusia yang lainnya bisa hidup bersama-sama, hingga memiliki karakter yang mirip. Teori ini cocok dengan penelitian yang diteliti, karena sama-sama mengungkap sebuah komunitas yang solid.

Karakter dipengaruhi oleh lingkungan dan gaya hidup masing-masing. Sebuah komunitas merupakan perkumpulan orang-orang yang memiliki tujuan yang sama sehingga cenderung memiliki dunia simbolik yang sama. Karena disetiap komunitas memiliki persamaan ideologi.

Table 2. Uji Validitas Variabel Independen

\begin{tabular}{clll}
\hline Item Pertanyaan & r Hitung & r Tabel & Keputusan \\
\hline P1 & 0,5355 & 0,2787 & Valid \\
P2 & 0,3665 & 0,2787 & Valid \\
P3 & 0,4308 & 0,2787 & Valid \\
P4 & 0,4003 & 0,2787 & Valid \\
P5 & 0,4542 & 0,2787 & Valid \\
P6 & 0,3714 & 0,2787 & Valid \\
P7 & 0,2918 & 0,2787 & Valid \\
P8 & 0,5618 & 0,2787 & Valid \\
\hline
\end{tabular}


Respon Komunitas Paradise Striver terhadap Dakwah Ustadz, Abu Takeru

\begin{tabular}{cccc}
\hline P9 & 0,3565 & 0,2787 & Valid \\
P10 & 1.0000 & 0,2787 & Valid \\
\hline
\end{tabular}

Sumber: Hasil SPSS 16.0

Berdasarkan pada Tabel 2 di atas menunjukkan bahwa seluruh pernyataan dalam variabel independen Respon Komunitas Paradise Striver adalah valid. Hal ini terlihat bahwa nilai pearson correlation (rhitung) setiap item pertanyaan lebih besar dari nilai rtabel dengan tingkat signifikasi untuk semua item pertanyaan pada level 0,05 .

\section{Penerimaan Komunitas Paradise Striver terhadap Pesan Dakwah Abu Takeru}

Respon penerimaan Komunitas Paradise Striver terhadap pesan dakwah Abu Takeru, dapat dilihat dari hasil analisi variabel y. Angket yang digunakan dalam penelitian ini merupakan angket tertutup, dalam artian responden tinggal memilih pernyataan yang telah tersedia tanpa ada desakan. Dalam bentuknya digunakan angket skala linkert dengan alternatif responden memilih jawaban yang telah ditentukan dalam bobot nilai 1-5 yang telah disediakan dengan sekala linkert sesuai dengan pernyataan yang diajukan pada responden.

Tabel. 3 Respon Penerimaan Komunitas Paradise Striver terhadap Pesan Dakwah Abu Takeru

\begin{tabular}{|c|c|c|c|c|c|}
\hline Pertanyaan & STS & TS & TP & $\mathbf{S}$ & SS \\
\hline $\begin{array}{l}\text { Berkaca dari kehidupan sehari- } \\
\text { hari Ustadz Rizal (Abu Takeru), } \\
\text { membuat saya mengerti bahwa } \\
\text { berdakwah tidak memandang usia. }\end{array}$ & 1 & - & 4 & 21 & 24 \\
\hline $\begin{array}{l}\text { Kesederhanaan Ustadz Rizal } \\
\text { (Abu Takeru) terutama dalam berpakaian } \\
\text { membuat saya mengerti, bahwa } \\
\text { berilmunya seseorang tidak dipandang } \\
\text { dari penampilan. }\end{array}$ & - & - & 6 & 20 & 24 \\
\hline $\begin{array}{l}\text { Ustdaz Rizal (Abu Takeru) sangat } \\
\text { menjungjung tinggi tatak rama (akhlak) } \\
\text { dalam prilaku sehari-hari, membuat saya } \\
\text { termotivasi untuk melakukan hal } \\
\text { tersebut. }\end{array}$ & - & - & 6 & 20 & 24 \\
\hline $\begin{array}{l}\text { Bahasa yang digunakan Ustadz } \\
\text { Rizal (Abu Takeru) dalam berdakwah, } \\
\text { sangat mudah dipahami. }\end{array}$ & - & - & 2 & 22 & 26 \\
\hline $\begin{array}{l}\text { Sedikitnya unsur humor (jenaka), } \\
\text { membuat saya lebih khusyuk dalam } \\
\text { mendalami pesan dakwah yang } \\
\text { disampaikan Ustadz Rizal (Abu Takeru). }\end{array}$ & 1 & 1 & 6 & 29 & 13 \\
\hline $\begin{array}{l}\text { Setelah mendengarkan dakwah } \\
\text { Ustadz Rizal (Abu Takeru) tentang Bab } \\
\text { Taubid, saya menjadi lebih khusyuk dalam } \\
\text { beribadah dan merasa dekat dengan }\end{array}$ & - & - & 6 & 26 & 18 \\
\hline
\end{tabular}


N. R. T. Wati, R. T. Rahman, \& U. Saepuloh

\section{Allah SWT.}

Dakwah Ustadz Rizal (Abu

Takeru) dapat mengupas permasalahan yang sering terjadi dalam kehidupan sehari-hari.

Pembahasan dakwah yang dijelaskan oleh Ustadz Rizal (Abu Takeru), setaraf dengan kebutuhan rohani sehari-hari.

Metode komunikasi dua arah dalam proses tanya jawab saat berdakwah, membuat saya puas dengan jawaban dari pertanyaan yang saya ajukan.

Setelah saya mendengarkan

dakwah Ustadz Rizal (Abu Takeru), membuat saya paham bahwa baik di mata manusia belum tentu baik di mata Allah SWT.

\section{Sumber: Instrumen Penelitian}

Teori citra da'i merupakan pendukung hasil analisis dari angket variabel y sebagaimana tabel 3 di atas, yang menjelaskan tentang kegiatan dakwah. Bahwa kesuksesan dakwah dapat dilihat dari kualitas dan kepribadian da'i. kualitas dapat menumbuhkan kepercayaan (kredibilitas) dengan bahasa dan cara penyampaian dakwah, yang akan melahirkan citra positif di hadapan mad'u. (Enjang dan Aliyudin, 2009:120)

Teori citra da'i digunakan karena sesuai dengan penelitian ini yaitu kegiatan dakwah. Dengan teori citra da'i, akan diketahui seberapa besar penilaian mad'u terhadap kredibilitas da'i. Penilaian tersebut, akan melahirkan respon positif maupun negatif dari mad'u sebagai nilai dari kegiatan dakwah yang dilakukan da'i. Dengan demikian, persepsi mad'u sangat berpengaruh besar dalam menentukan apakah mad'u menerima pesan dakwah yang disampaikan da'i atau tidak.

Kredibilitas da'i bisa dilihat dari bahasa yang digunakan da'i dalam menyampaikan dakwah, harus sesuai dengan AL-Qur'an dan AS-Sunnah. Maka seorang da'i tidak boleh memiliki akhlak yang jelek. Kredibilitas ini berpungsi bukan hanya untuk nama baik da'i saja, melainkan yang terpenting citra Islam terjaga. Dengan demikian, kedua teori yang dibahas memberi pengaruh terhadap penelitian yang diteliti.

Tabel 4. Hasil Uji Validitas Variabel Dependen

\begin{tabular}{|c|c|c|c|}
\hline Item Pertanyaan & $\mathrm{r}$ hitung & $\mathrm{r}$ tabel & Keputusan \\
\hline P1 & 0,6144 & 0,2787 & Valid \\
\hline P2 & 0,6944 & 0,2787 & Valid \\
\hline P3 & 0,8230 & 0,2787 & Valid \\
\hline P4 & 0,6671 & 0,2787 & Valid \\
\hline
\end{tabular}


Respon Komunitas Paradise Striver terhadap Dakwah Ustadz, Abu Takeru

\begin{tabular}{|c|c|c|c|}
\hline P6 & 0,5919 & 0,2787 & Valid \\
\hline P7 & 0,4653 & 0,2787 & Valid \\
\hline P8 & 0,7720 & 0,2787 & Valid \\
\hline P9 & 0,6888 & 0,2787 & Valid \\
\hline P10 & 0,7558 & 0,2787 & Valid \\
\hline
\end{tabular}

Sumber: Hasil SPSS 16.0

Berdasarkan pada tabel 4 di atas menunjukan bahwa seluruh pernyataan dalam variabel dependen Dakwah Ustadz Rizal (Abu Takeru) adalah valid. Hal ini terlihat bahwa nilai pearson correlation ( $\mathrm{r}$ hitung) setiap item pertaanyaan lebih besar dari nilai $r$ tabel dengan tingkat signifikasi untuk semua item pertanyaan pada level 0,05.

Tabel 5. Uji Reliabilitas Variabel Independen

\begin{tabular}{|c|c|}
\hline \\
\hline \multicolumn{2}{|l|}{$\begin{array}{l}\text { Alpha } \\
\text { Based on }\end{array}$} \\
\hline Standa & \\
\hline ed & $\mathrm{N}$ of \\
\hline Items & Items \\
\hline .877 & 10 \\
\hline
\end{tabular}

Tabel 5 di atas merupakan hasil pengujian reliabilitas Respon Komunitas Paradise Striver, menunjukan bahwa nilai Combach's Alpha lebih besar dari $60 \%$ $(0,06)$ yaitu $8,77 \%(0,877)$. Dengan demikian, pernyataan yang menunjukan respon pada Komunitas Paradise Striver sangat reliabel yang dapat diterima dalam instrumen penelitian.

Tabel 6. Uji Reliabilitas Variabel Dependen

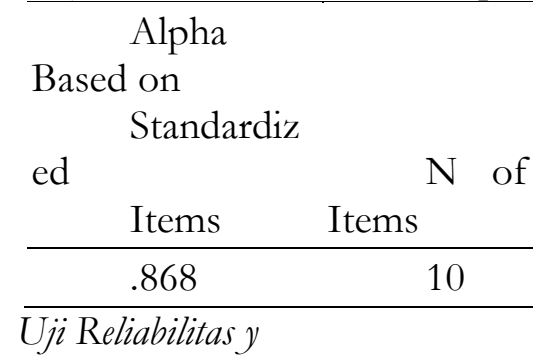

Dari tabel 6 di atas tentang hasil pengujian realibitas Dakwah Abu Takeru di atas menunjukan bahwa nilai Cronbach's alpha lebih besar dari 0,60 yaitu 0,868. Hal ini menunjukan bahwa butir pernyataan yang terdapat dalam variabel dakwah Abu Takeru realibel yang dapat diterima sebagai alat ukur suatu instrument 
penelitian.

Tabel 7. Hasil Regresi Linear Sederhana

\begin{tabular}{|c|c|c|c|c|c|c|}
\hline & & ized ( & $\begin{array}{l}\text { Unstandar } \\
\text { oefficients }\end{array}$ & $\begin{array}{l}\text { Stand } \\
\text { d ardized } \\
\text { Coefficients }\end{array}$ & & \\
\hline Model & & & Bd. Error & Beta & & Tig. \\
\hline 1 & (Constan & & 1 & & & 3 \\
\hline & t) & 1.833 & 627 & & .263 & 002 \\
\hline & $\begin{array}{l}\quad \text { Respon } \\
\text { Komunitas } \\
\text { Paradise Striver }\end{array}$ & & .0 & 783 & & 8 \\
\hline & & 718 & 82 & .83 & .710 & 000 \\
\hline
\end{tabular}

Dependent variable: Dakwah ustadz Rizal (Abu takeru)

Sumber: Hasil Pengolahan Data SPSS 16.0

Berdasarkan tabel di atas Respon Komunitas Paradise Striver $(X)$ terhadap Dakwah Ustadz Rizal (Abu Takeru) (Y). Pada kolom koefisien terdapat nilai signifikansi 0,002. Nilai signifikansi lebih besar daripada nilai probabilitas 0,05 atau nilai $0,002<0,05$. T hitung pada tabel gambar 7 di atas sebesar 3.263 sedangan t tabel dalam penelitia ini 2,011, sehingga t hitung $>$ t tabel.

Tabel 8. Hasil Uji t 


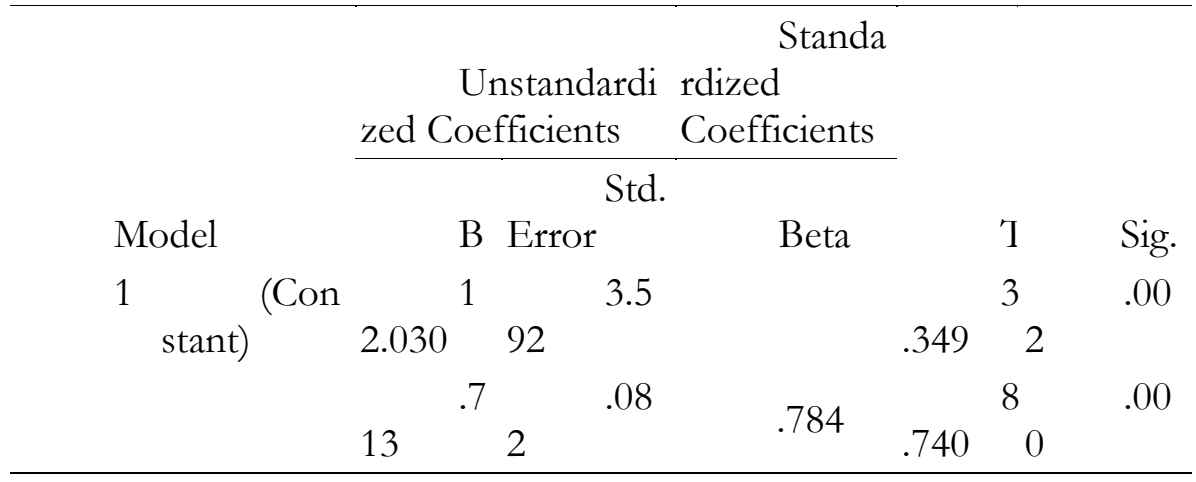

a. Dependent Variable: Dakwah Ust. Rizal (Abu

Takeru)

Berdasarkan tabel di atas Respon Komunitas Paradise Striver $(X)$ terhadap Dakwah Ustadz Rizal (Abu Takeru) (Y). Pada kolom koefisien terdapat nilai signifikansi 0,002 . Nilai signifikansi lebih besar daripada nilai probabilitas 0,05 atau nilai $0,002<0,05$, maka $\mathrm{Ha}$ diterima dan $\mathrm{Ho}$ di tolak. Dengan ketentuan bahwa tingkat signifikansi taraf nyata (level of significance) sebesar 5\% atau $\alpha=$ 0,05. Derajat kebebasan (degreeof freedom) atau DF $=\mathrm{n}-\mathrm{k}-1$ atau $\mathrm{DF}=50-2-1$ $=$ 47. Maka $\mathrm{T}$ tabel adalah 2,011. Variabel $X$ mempunyai $\mathrm{T}$ hitung 3,349 dengan tabel sebesar 2,011 jadi tThitung $>$ Ttabel. Jadi dapat disimpulkan Respon Komunitas Paradise Striver berpengaruh signifikan terhadap Dakwah Ustadz Rizal (Abu Takeru).

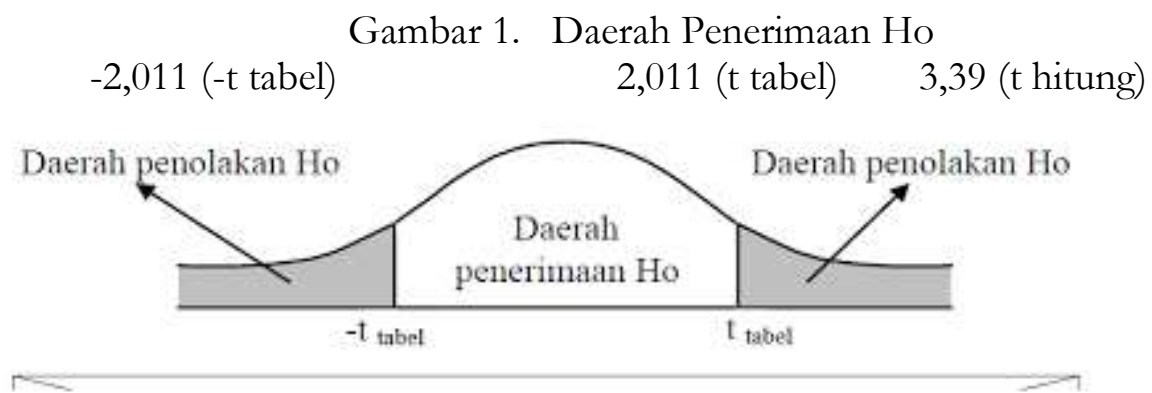

Dari gambar 1 di atas dapat dilihat bahwa thitung berada pada daerah penolakan Ho dengan tingkat signifikan diketahui adalah menunjukan hubungan antara Respon Komunitas Paradise Striver terhadap Dakwah Rizal (Abu Takeru) adalah signifikan karena 0,002 <0,05. Maka dapat disimpulkan bahwa terdapat pengaruh positif yang signifikan antara Respon Komunitas Paradise Striver terhadap Dakwah Rizal (Abu Takeru).

Tabel 9. Hasil Analisis Regresi Secara Bersama-sama (Uji f) 


\begin{tabular}{|c|c|c|c|c|c|}
\hline \multirow[b]{3}{*}{ Model } & $\mathrm{Su}$ & \multirow{2}{*}{\multicolumn{4}{|c|}{ Mean }} \\
\hline & $\mathrm{m} \quad$ of & & & & \\
\hline & Squares & \multicolumn{3}{|c|}{ Df Square } & $\mathrm{F}$ \\
\hline Regre & 694 & \multirow{2}{*}{1} & \multirow{2}{*}{694.550} & \multirow{2}{*}{\multicolumn{2}{|c|}{864}} \\
\hline ssion & .550 & & & & \\
\hline Resid & 439 & \multirow{2}{*}{48} & \multirow{2}{*}{9.155} & & \\
\hline ual & .450 & & & & \\
\hline Total & 113 & \multirow{2}{*}{49} & & & \\
\hline & 4.000 & & & & \\
\hline
\end{tabular}

Predictors: (Constant), Respon Komunitas Paradise Striver

Dependent Variable: Dakwah Ustadz. Abu Takeru

Dari tabel 9 di atas diperoleh nilai $F$ Hitung untuk model regresi yang digunakan sebesar 75,864 Untuk memperoleh Ftabel dengan menggunakan dengan menggunakan tingkat keyakinan $95 \%, \alpha=5 \% \mathrm{dk}(2-1)=2$, dan $\mathrm{dk}(50-2-$ $1)=47$, hasil diperoleh untuk Ftabel sebesar 3,20. Nilai Fhitung $>$ Ftab $(75,864>3,20)$ maka $H o$ ditolak, artinya terdapat respon secara signifikan Komunitas Paradise Striver terhadap Dakwah Abu Takeru.

Pengujian secara simultan $X$ terhadap $Y$ dari tabel diperoleh nilai $F$ hitung sebesar 75,864 dengan nilai probabilitas (signifikansi) $=0,000$. Nilai $F$ bitung 75,864>Fta 3,20, dan nilai signifikansi < dari nilai Probabilitas 0,05, maka $\mathrm{Ha}$ diterima dan $H o$ ditolak, berarti secara bersama-sama atau simultan Respon Komunitas Paradise Striver beperngaruh signifikan terhadap Dakwah Abu Takeru penelitian di Masjid AL-asy'ari Tamansari Kota Bandung.

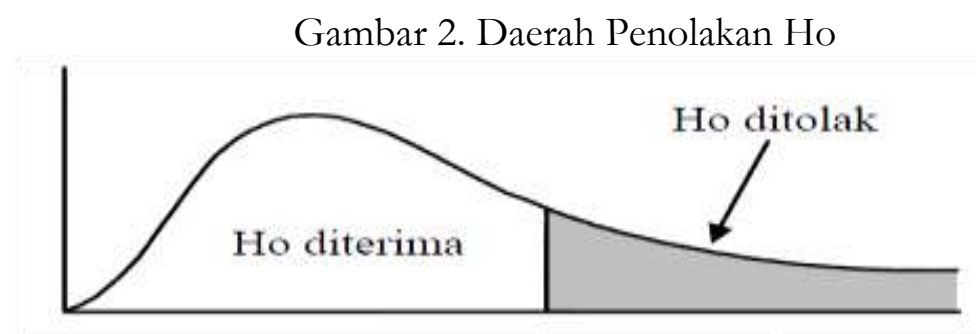

F tabel $(3,20) \quad$ f hitung $(75,864)$

Dari gambar 2 di atas dilihat bahwa dari gambar tersebut dapat dilihat bahwa Fbitung berada pada daerah penolakan Ho, maka dapat diartikan bahwa terdapat respon positif antara Komunitas Paradise Striver (x) terhadap Dakwah Abu Takeru (y). 
Tabel 10. Matriks Korelasi

Respon

Komunitas Paradise

Dakwah Ustadz

Striver

Abu Takeru

\begin{tabular}{llll}
\hline Respon & Pearson & 1 & $.783^{* *}$ \\
$\begin{array}{l}\text { Komuni Correlation } \\
\text { tas }\end{array}$ & Sig. (2-tailed) & & .000 \\
$\begin{array}{l}\text { Paradise } \\
\text { Striver }\end{array}$ & $\mathrm{N}$ & 50 & 50 \\
$\begin{array}{l}\text { Dakwah } \\
\text { Ustadz }\end{array}$ & Correlation & & \\
Abu & Sig. (2-tailed) & $.783^{* *}$ & 1 \\
Takeru & $\mathrm{N}$ & .000 & \\
& 50 & 50
\end{tabular}

Sumber: Hasil pengolahan data menggunakan SPSS 16.0

Berdasarkan tabel 10 di atas dapat diketahui bahwa korelasi antara Respon Komunitas Paradise Striver (x) terhadap Dakwah ustadz Rizal (Abu Takeru) (y) sebesar 0,783 dengan tingkat signifikan sebesar 0,000. Berdasarkan tabel pedoman interpretasi, nilai tersebut menunjukan tingkat korelasi cukup kuat. Nilai korelasi yang positif menunjukan bahwa Respon Komunitas Paradise Striver (x) terhadap Dakwah Abu Takeru (y) semakin tinggi, maka responpun semakin tinggi.

Tabel 11. Hasil Analisis Koefisien Determinasi Model Summary

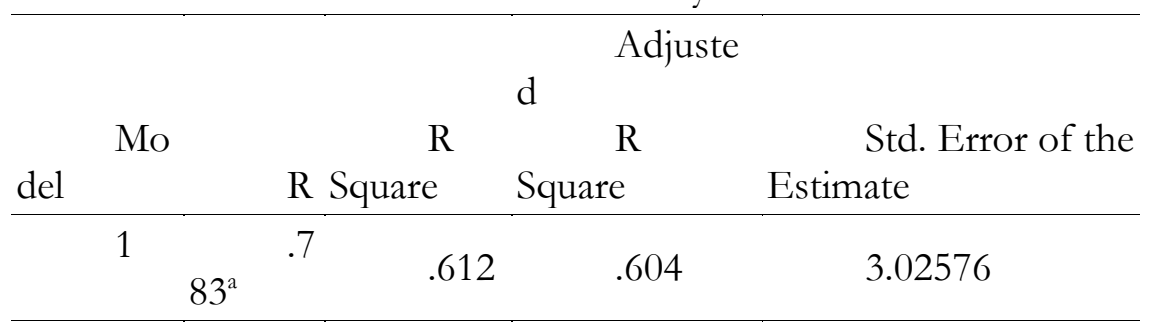

Predictors: (Constant), Respon Komunitas Paradise Striver

Dependen Variabel : Dakwah Ustadz Rizal Fadli Nurbadi (Abu Takeru)

Dari hasil tabel 11 di atas dapat dilihat bahwa angka $R 2$ (R Square) sebesar 0,612 atau $61,2 \%$. Hal ini menunjukan bahwa persentase respon variabel independen (variabel $\mathrm{x}$ ) terhadap variabel dependen yaitu Dakwah Abu Takeru sebesar 61,2\% dengan tingkat signifikansi yang kuat sesuai dengan Kaidah Reliabilitas Triton, atau variasi variabel independen yang digunakan dalam dimensi Respon Komunitas Paradise Striver, mampu menjelaskan sebesar 61,2\% variasi variabel dependen Dakwah Abu Takeru sedangkan sisanya 38,8\% dipengaruhi atau dijelaskan oleh varibel lain yang tidak diteliti oleh peneliti. 
Dengan demikian Respon Komunitas Paradise Striver terhadap Dakwah Abu Takeru memiliki respon positif yang cukup kuat. Baik dari segi keilmuan Abu Takeru maupun dari akhlak sehari-hari Abu Takeru. Sehingga kajian Abu Takeru mendapatkan respon positif dari berbagai pihak, baik anggota Komunitas Paradise Striver maupun masyarakat luar. Hal ini dibuktikan dengan hasil kuesioner, wawancara dengan anggota komunitas, dan masyarakat sekitar tempat kajian Abu Takeru.

\section{PENUTUP}

Respon perhatian, pengertian, dan penerimaan Komunitas Paradise Striver terhadap Dakwah Abu Takeru di Masjid AL-Asy'ari berada dalam kategori kuat. Dakwah yang di bawakan Abu Takeru memiliki kredibilitas yang tinggi, dan mendapatan respon positif baik dari strategi maupun metode yang di gunakan. Dilihat dari latar belakang Abu Takeru yang cukup dalam menggali ilmu agama islam di East Preston Collage, selama tiga tahun. Selama di East Preston Collage Abu Takeru sempat belajar pada teman-teman Dr. zakir Naik yang sedang melakukan dauroh di Melbourne University. Kemudian beliau juga aktif dalam organisasi ke islaman di masa SMAnya. Abu Takeru pernah menjadi Ketua Lembaga Dakwah, dan pernah beberapa kali menjadi juara MTQ. Sehingga ilmu beliau tidak di ragukan lagi.Materi yang di sampaikan sesuai dengan kebutuhan dan problematika kehidupan sehari-hari anggota Komunitas Paradise Striver dan masyarakat sekitar.

Hasil penelitian menunjukan angka $R 2$ (R Square) sebesar 0,612 atau 61,2\%. Hal ini menunjukan bahwa persentase respon variabel independen (variabel $\mathrm{x}$ ) terhadap variabel dependen yaitu Dakwah Abu Takeru sebesar 61,2\% dengan tingkat signifikansi yang kuat sesuai dengan Kaidah Reliabilitas Triton. Atau variasi variabel independen yang digunakan dalam dimensi Respon Komunitas Paradise Striver, mampu menjelaskan sebesar 61,2\% variasi variabel dependen Dakwah Abu Takeru sedangkan sisanya 38,8\% dipengaruhi atau dijelaskan oleh varibel lain yang tidak diteliti oleh peneliti.

Dari sekian banyak pembahasan yang dijelaskan, maka dapat ditarik kesimpulan sebagai berikut: Pertama, da'I yang menyam paikan dakwah (Abu Takeru) dapat diterima dengan baik oleh anggota komunitas. Sikap dan prilaku sehari-hari Abu Takeru sangat baik dan sederhana, sehingga tidak ada permasalahan antara anggota Komunitas Paradise Setriver maupun masyarakat sekitar terhadap gaya hidup Abu Takeru sebagai da'i. Kedua, pesan dakwah yang disampaikan dalam kajian Abu Takeru sangat mudah dipahami, dan mampu mengupas segala problematika yang ada di kehidupan sehari-hari. Ketiga, dakwah yang dibawakan Abu Takeru bisa diterima oleh anggota Komunitas Paradise Striver dan masyarakat sekitar. Karena didalamnya tidak ada unsur ekstrim, semua bersumber dari AL-Qur'an dan AS-Sunnah.

Adapun saran dari penelitian ini sebagai berikut: pertama, untuk meningkatkan keberhasilan dakwah, alangkah baiknya Abu Takeru dan team 
mengadakan kajian secara menyeluruh ke daerah-daerah yang rawan akidah, tanpa menunggu undangan. Kedua, untuk keberhasilan Komunitas Paradise Striver, alangkah baiknya bisa lebih mengimbangi antara online dan offline agar balance. Karena tidak semua orang aktif di media social, agar semua orang bisa merasakan kehadiran Komunitas Paradise Striver di lingkungan masyarakat. Ketiga, Bagi peneliti berikutnya sebaiknya menggunakan kuesioner yang bersifat senior-rating (dijawab oleh orang-orang senior, bukan jama'ah melainkan para mujahid dakwah yang memeberikan respon langsung terhadap Abu Takeru, sehingga dapat diperoleh pengukuran respon yang lebih obyektif.

\section{DAFTAR PUSTAKA}

Al Qahthani, Said bin Ali. 1994. Da'wah Islam Da'wah Bijak. Jakarta: Gema Insani Press. Hal 100.

Anshary, Isa. 1991. Mujahid Dakwah (Pembimbing Mubaligh Islam). Bandung: Cv. Diponegoro. Hal. 22.

Enjang, dan Aliyudin. 2009. Dasar-Dasar Ilmu Dakwah. Bandung: Widya Padjaja ran. Hal. 120.

Hafidhuddin, Didin.1998. Dakwah Aktual. Jakrata: Gema Insani Press. Hal. 82.

Hasjmy, A. 1974. Dustur Dakwah Menurut Al-Qur'an. Jakarta: PT Bulan Bintang. Hal. 20.

Muthahhari, Murthada. 1997. Akblak Suci Nabi yang Ummi. Bandung: Mizan. Hal. 67.

Suryabrata, Sumadi. 1998. Metodologi Penelitian. Jakarta: PT Raja Grafindo Persada. Hal. 18.

Zahrah, Abu. 1994. Dakwah Islamiah. Bandung: PT Remaja Rosdakarya Offset. Hal. 76.

Majid Khon, Abdul. 2011. Pemikiran Modern dalam Sunnab Pendekatan Ilmu Hadis. Jakarta: Kencana Prenada Media Group. Hal. 8.

Uchjana Effendy, Onong. 2003. Ilmu, Teori dan Filsafat Komunikasi. Bandung: PT Citra Aditya Bakti. Hal. 132.

Tarwiyah, Siti. 2016. Respon Netizen terhadap Dakwah Bi al-Qolam K. H. Muhammad Arifin Ilham di Media Sosial: Academic Journal For Homiletic Studies. Hal. 94.

Takmir Masjid AL-Asy'ari. 2011. Lembaga Studi Islam Madani (Hidup Mulia atau Mati Syahid). Diposting: Kamis, 20 Oktober $2011 . \quad$ Dari http://www.lembagastudiislam. 
N. R. T. Wati, R. T. Rahman, \& U. Saepuloh 